\title{
Cryopreservation of Complex Systems: The Missing Link in the Regenerative Medicine Supply Chain
}

\author{
GREGORY M. FAHY, BRIAN WOWK, and JUN WU
}

\begin{abstract}
Transplantation can be regarded as one form of "antiaging medicine" that is widely accepted as being effective in extending human life. The current number of organ transplants in the United States is on the order of 20,000 per year, but the need may be closer to 900,000 per year. Cadaveric and living-related donor sources are unlikely to be able to provide all of the transplants required, but the gap between supply and demand can be eliminated in principle by the field of regenerative medicine, including the present field of tissue engineering through which cell, tissue, and even organ replacements are being created in the laboratory. If so, it could allow over $30 \%$ of all deaths in the United States to be substantially postponed, raising the probability of living to the age of 80 by a factor of two and the odds of living to 90 by more than a factor of 10 . This promise, however, depends on the ability to physically distribute the products of regenerative medicine to patients in need and to produce these products in a way that allows for adequate inventory control and quality assurance. For this purpose, the ability to cryogenically preserve (cryopreserve) cells, tissues, and even whole laboratory-produced organs may be indispensable. Until recently, the cryopreservation of organs has seemed a remote prospect to most observers, but developments over the past few years are rapidly changing the scientific basis for preserving even the most difficult and delicate organs for unlimited periods of time. Animal intestines and ovaries have been frozen, thawed, and shown to function after transplantation, but the preservation of vital organs will most likely require vitrification. With vitrification, all ice formation is prevented and the organ is preserved in the glassy state below the glass transition temperature $\left(T_{G}\right)$. Vitrification has been successful for many tissues such as veins, arteries, cartilage, and heart valves, and success has even been claimed for whole ovaries. For vital organs, a significant recent milestone for vitrification has been the ability to routinely recover rabbit kidneys after cooling to a mean intrarenal temperature of about $-45^{\circ} \mathrm{C}$, as verified by life support function after transplantation. This temperature is not low enough for long-term banking, but research continues on preservation below $-45^{\circ} \mathrm{C}$, and some encouraging preliminary evidence has been obtained indicating that kidneys can support life after vitrification. Full development of tissue engineering and organ generation from stem cells, when combined with the ability to bank these laboratory-produced products, in theory could dramatically increase median life expectancy even in the absence of any improvements in mitigating aging processes on a fundamental level.
\end{abstract}

21st Century Medicine, Inc., Rancho Cucamonga, California. 


\section{INTRODUCTION}

C RYOBIOLOGY, THE SCIENCE OF LIFE at low temperatures, is a broad and dynamic area of basic and applied research that is becoming increasingly important for the practice of medicine. Sperm banking, frozen blood, and frozen human embryos are longstanding and well-known medical contributions of the field of cryobiology outside the treatment of aging. More recently, the principles of cryobiology have begun to be applied to the products of regenerative medicine and thereby to the problems of aging. Of particular note is the fact that human embryonic stem cells have been cryopreserved successfully ${ }^{1}$ and are now available for attempts at rejuvenation. ${ }^{2}$ More broadly, successes in freezing human ova ${ }^{3}$ and ovarian tissue ${ }^{4}$ promise to allow women to prolong their fertile years and survive cancer with their fertility intact, and the practice of freezing cord blood stem cells for uses that may well involve rejuvenatory medicine in the future also has become well known. Other proposed applications of cryopreservation (preservation at cryogenic temperatures) to the treatment of aging are feasible in principle but have yet to be realized in practice. Many years ago, Makinodan and colleagues 5 proposed that healthy $\mathrm{T}$ cells be collected in youth, frozen, and given back to the donor in old age to correct immunodeficiency. As immunologic tolerance induction becomes more successful, cryopreservation of young donor organs to allow time for donor-specific tolerance to be developed in the planned older recipient ${ }^{6,7}$ could have a major impact on the present field of transplantation. The focus of the present paper is on the relevance of cryopreservation to the next few steps in regenerative medicine, in which increasingly complex new products of tissue engineering and stem cell biology are successfully applied to the correction of age-related deficits. This prospect brings with it both greatly improved scope for major amelioration of aging and greatly increased requirements for advanced cryopreservation technology.

\section{TRANSPLANTATION AS A BRANCH OF REJUVENATORY MEDICINE}

Aging entails both the loss of cells and the loss of the functional capacity of organs. There- fore, reversal of aging symptoms may be achievable, at least in part, by replacing cells that have been lost and organs whose function is no longer adequate. On this basis, transplantation can be seen as a form of piecemeal rejuvenation or "brute force rejuvenation" that is in fact clearly successful at extending the human lifespan even with the current limitations of immunosuppressive therapy.

Unfortunately, human cadaver sources of replacement tissues and organs have been notoriously inadequate for many years, and xenografts remain problematic. Accordingly, as of 2001, there were 73 US companies devoted to tissue engineering and regenerative medicine and at least 16 counterparts in Europe and Australia, all devoted to closing the gap between the supply and demand for cells, tissues, organs, and structural elements. ${ }^{8}$ The US annual expenditure for these efforts was over $\$ 600$ million, and the estimated total value of these companies was as much as $\$ 7$ billion. ${ }^{8}$ More recently, the obstacles to making the transition from the laboratory to the clinic have winnowed the field considerably, ${ }^{9}$ but both the total investment made to date and the persistence of substantial ongoing efforts testifies to the basic and persistent need for transplantable replacements.

An idea of the potential need for laboratory created substitutes for vital organs alone can be gleaned from an analysis of mortality data compiled in the National Vital Statistics Report. ${ }^{10}$ Table 1 shows the annual death rates caused by organ failure that could in principle be corrected by transplantation. Of the four organs whose failure is responsible for the most deaths each year, the heart makes the greatest contribution by far. Together, the preventable deaths listed in Table 1 account for nearly 900,000 deaths per annum, or a staggering $36 \%$ of the total US death rate from all causes. By comparison, the number of human organ transplants carried out annually in the United States today is only on the order of 20,000 , or about $2 \%$ of the total number needed.

Figure 1 presents a reconstruction of the present human mortality curve from available statistics on age-specific death rates from all causes and compares it to the expected mortality curve if the deaths described in Table 1 could be prevented by organ transplantation. 
Table 1. Contribution of Deaths Preventable By TRANSPLANTATION TO THE TOTAL Death Rate in the United States

\begin{tabular}{lc}
\hline Organ & $\begin{array}{c}\text { Annual US deaths caused } \\
\text { by organ failure that could } \\
\text { be treated by transplantation }\end{array}$ \\
\hline Heart & 710,760 \\
Lung & 122,009 \\
Kidney & 37,251 \\
Liver & 16,214 \\
All of the above & 886,234 \\
All of the above, per day & 2,428 \\
All of the above, as a & $36.2 \%$ \\
percentage of total & \\
US mortality & \\
\hline
\end{tabular}

aBased on total 2005 US annual mortality.

From: Table 1. Natl Vital Stat Rept 2002;50(16):15-48.

Each year, all newly surviving transplant recipients are assumed to be subject to all other nonexcluded causes of death with the same probabilities as prevail for the rest of the population. The results of intervention as estimated in this way are highly significant. According to this analysis, comprehensive replacement of the most critical four organs as needed would double the likelihood of reaching the age of 80 and would increase the probability of living to the age of 90 by nearly 20-fold. Although much of this benefit will undoubtedly be achieved by other means, such as lifestyle changes and statins to reduce cardiovascular risk factors, there will undoubtedly remain a major need for organ replacement for many years to come.

\section{THE NEED FOR CRYOPRESERVATION}

What has been overlooked generally in the global effort in regenerative medicine is the significance of the gap in time that must exist normally between the moment a given replacement is created and the occasion of its final transplantation. In some cases, particularly in a scenario in which replacements are made that are genetically identical to the recipient and plenty of time is available to produce and transplant the constructs, this gap may be short and insignificant. However, this scenario has limitations of economic viability, flexibility of scheduling, inability to supply replacements in case of acute injury or illness, and inability to produce replacements long in advance of need unless cryopreservation is available (Table 2). Greater economic viability could be achieved in a scenario of mass-produced allografts enjoying the major economies of scale associated with such a production mode. In this scenario, life-saving constructs would be produced and distributed with the benefit of donor-specific tolerance induction, the feasibility of which has already been strongly supported, ${ }^{11-16 a}$ and the gap between production and use of replacements generally would be much longer than can be appropriately managed by continued maintenance at $37^{\circ} \mathrm{C}$ or refrigeration (see

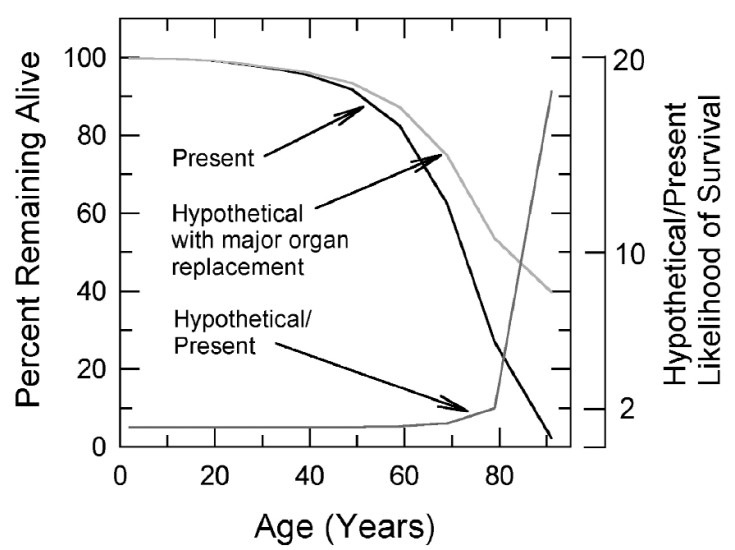

FIG. 1. Projected potential effect of heart, lung, kidney, and liver replacement on the human mortality curve, assuming no bottlenecks in organ supply, no surgical deaths, and no deaths from immunosuppression. All other causes of death in the general population are assumed to occur with the same prevalence in transplanted and nontransplanted individuals of the same ages before and after transplantation. The control curve (black) was constructed as follows. First, $100 \%$ (the survival rate at age zero) was multiplied by the infant mortality rate and the result was subtracted from $100 \%$ to yield the starting survival percentage for the same cohort over the next age interval. Second, this process was repeated, age by age, to obtain the cumulative effect of age-specific mortality until the age of 80 . After the age of 80 , age-specific mortality data were sparse and were estimated from the overall mortality rates at ages 85 and $85+$. The effect of transplantation (upper curve) was estimated using the same method but, at each age, subtracting the fraction of deaths that would be likely to be preventable by transplantation from the total mortality rate for that age. The final curve is the ratio of the modified mortality curve to the preintervention curve and represents the age-specific increase in the probability of survival expected as a result of comprehensive and fully successful major organ transplantation. Interestingly, the effect is most pronounced at more advanced ages because the death rates at younger ages result more from cancer than organ failure, whereas at more advanced ages organ failure outstrips cancer as the leading cause of death. Results for all races and both sexes. 
Table 2. Supply Chain Management Issues in Regenerative Medicine

For allografts (assuming tolerance induction; manufactured or natural organs)

1. It must be possible to ship inventory to any desired location to allow wide geographic distribution without product deterioration en route.

2. After shipment, it must be possible for inventory to be stored in local hospitals until needed.

3. Inventory reserves must be available to meet sudden unforeseen increases in demand (natural disasters, accidents, terrorist attacks, wars).

4. It is necessary to retain flexibility of production (to allow retooling for process modifications, emergency shutdowns for repairs, decontamination, or inspections) without interruptions in supply.

5. Quality control issues include the desirability of: lot archiving for subsequent quality analysis; lot quarantine to meet regulatory requirements; large lot sizes to ensure product consistency over time; lot protection from contamination and genetic drift.

6. Natural organ allografts may require weeks or months of banking to permit donor-specific tolerance induction before transplantation.

For autografts (either natural or laboratory produced and genetically identical to the recipient)

1. Some organs may be removed during chemotherapy and/or radiation therapy for cancer, banked, and replaced after cancer eradication.

2. Organs for slowly developing diseases such as end-stage renal failure may be produced well in advance of the unpredictable time of need so as to be available without long delays when the need arises.

3. In some cases, like spare tires, individual-specific organs may be banked in local hospitals in case of sudden need (accidents, disease, attempted homicide, occupational hazards).

4. In some cases, organs produced for elective use may be banked if something interferes with their scheduled transplantation.

Table 2). According to former officials of the now-defunct Advanced Tissue Sciences, Inc., a minimum storage period of 3 to 6 months is necessary for the adequate management of the regenerative medicine supply chain even for a relatively simple engineered tissue such as skin (Applegate, personal communication). Even if it were technically feasible to maintain manufactured tissues and organs indefinitely in culture at $37^{\circ} \mathrm{C}$, the cost would become prohibitive over 3 to 6 months or longer, ${ }^{17}$ and there would be a constant danger of bacterial or viral contamination and genetic drift. By comparison, maintenance in liquid nitrogen is very inexpensive, and cryopreservation is the only preservation approach that can allow any desired storage time to be selected as required by changing circumstances. Because cooling to below $\mathrm{T}_{\mathrm{G}}$ arrests biologic changes over time, cryopreservation would make tissue archiving possible for quality assurance purposes, and large inventories could be prepared and stored to ensure product uniformity over time ${ }^{18}$ without concern over outdating. Other critical applications of cryopreservation as listed in Table 2 are self-explanatory.

In principle, the use of stem cells to repair organs in situ in the living patient would obviate the need for exogenously produced transplants and would be a less traumatic and much less costly remedy for the current organ failure problems. ${ }^{19,20}$ In practice, the ability to control stem cell targeting and differentiation in vivo, although quite promising, is still in its infancy, and involves many unanswered questions about safety, efficacy, and adequacy. ${ }^{21}$ An organ already ravaged with disease and burdened by extensive fibrosis may not always be reparable by the mere presence of stem cells in the vicinity of diseased cells. Such an organ may require in addition the targeted death of the diseased cells to make way for new cell replacements and/or a method for removing scar tissue to allow the invasion of new cells. ${ }^{19,22}$ The arts of selectively clearing diseased but not dead cells and scar tissue from amidst healthy tissue are far from established at the present time. In addition, concerns over tumorigenicity of undifferentiated stem cells remain (e.g., see Ref. 22a). Questions also exist concerning the ability of stem cell treatments to reverse damage to nonliving extracellular structures important for organ function, such as the glomerular basement membrane of the kidney. The simple excision of unwanted tissues or organs and their replacement with more youthful tissues and organs that have been fully, stably, and reliably differentiated in vitro is a more foolproof scenario for the time being. It is also the scenario in which the greatest investments 
of time, money, and personnel have been made to date. Ultimately, in vivo stem cell therapy ${ }^{19}$ or endogenous stem cell creation or activation ${ }^{20}$ and endogenous regeneration ${ }^{22}$ will surely be the future of medicine. However, in the interim the more traditional approach of transplantation may provide more immediate help to patients who cannot wait for more sophisticated methods to be developed.

Regenerative medicine has had many successes, and many promising designs are in development. ${ }^{23}$ For engineered cells and simple engineered tissue, traditional methods of cryopreservation may well be adequate. ${ }^{24}$ Attempts to reconstruct large whole organs are relatively rare, but major successes already have been achieved. The bioartificial liver is a particularly prominent example of a device created entirely in vitro, ${ }^{25}$ and important strides also are being made in the development of bioartificial cardiac assist devices. ${ }^{25 a}$ Perhaps the most impressive achievement in the field to date is the creation of whole, functioning proto-kidneys from bovine embryonic stem cells made by somatic cell nuclear transfer and their long-term survival after transplantation into the nuclear donor. ${ }^{26}$ However, spectacular success also has been achieved in the creation of artificial vaginas, uteruses, bladders, urethras, and other constructs that are presently functioning in real human patients. ${ }^{26 a}$ Therefore, although mass supplies of US Food and Drug Administration-approved extracorporeal or permanently implantable organ substitutes are undoubtedly still years away, it appears likely that they are indeed on the way. When they arrive, methods for their long-term preservation will be necessary, and conventional freezing methods will not be equal to the task. ${ }^{27-29}$

Given that the development of methods that will be able to meet the challenges of preserving complex vascularized extended systems also will be complex and will require time, it is fortunate that research on the preservation of whole organs at cryogenic temperatures is already well underway. In the meantime, methodology being developed at the authors' laboratory for the preservation of large organs is finding very important applications for the preservation of simpler systems of great im- portance in regenerative and rejuvenatory medicine today. ${ }^{30}$

\section{ORGAN CRYOPRESERVATION BY FREEZING}

The earliest attempts to achieve the successful cryopreservation of whole mammalian organs involved freezing. In the late 1950s, Smith and Farrant were able to show the recovery of contractile responses in guinea pig uteri in vitro after freezing to the temperature of dry ice and thawing, ${ }^{31}$ but they did not attempt to transplant these organs. Hamilton, Holst, and Lehr achieved the next major breakthrough in 1973, freezing lengths of dog intestine in liquid nitrogen, thawing them, and obtaining long-term survival of a minority of these segments after transplantation. ${ }^{32}$ In 2002, considerable attention was given to a report of partial success with intact rat ovaries ${ }^{33}$ that were frozen, thawed, and transplanted by vascular anastomosis. A minority of these ovaries survived, but one survivor was able to give rise to developing pups. $^{33}$ Unfortunately, this model does not really test the suitability of vascular preservation after whole organ freezing because rodent ovaries can survive freezing, thawing, and transplantation even without vascular anastomosis ${ }^{34,35}$ and can even selfassemble from enzymatic digests of ovarian tissue and form pups after natural mating. ${ }^{36} \mathrm{~A}$ report of the freezing, thawing, and transplantation of sheep ovaries appeared in $2003 .{ }^{37}$ Vascular patency was retained in three of 11 grafts, and follicle-stimulating hormone levels were kept to within normal limits by the three surviving grafts. ${ }^{37}$ A second report claims higher patency rates using a directional freezing approach, ${ }^{38}$ but damage remained extensive. ${ }^{39}$ Although this might represent a step forward for the reversal of sterility after chemotherapy, it is unlikely to be an optimal approach (see the following).

It remains the case that no vital organ (particularly a heart, liver, or kidney) has ever been frozen to a temperature low enough for longterm storage and subsequently thawed, transplanted, and found to support life, let alone to do so on a consistent and reliable basis. The rea- 
sons for this failure are numerous, ${ }^{40}$ but one of the most critical problems is vascular damage ${ }^{41-43}$ A great deal of vascular damage was undoubtedly induced by freezing in the canine intestine and sheep ovary, but both are able to accommodate substantial edema without developing tissue pressure sufficient to terminate further perfusion, so this injury can be healed in some cases. Unfortunately, in vital organs such as the heart, liver, and kidney, vascular damage leads to permanent vascular obstruction and tissue necrosis.

Vascular damage from freezing is apparently a consequence of mechanical effects of ice on the vascular wall $28,42-44$ and can be induced by the formation of very little ice. ${ }^{41}$ Consequently, if the reliable banking of vascularized natural or bioartificial organs is to be feasible, the formation of ice must be minimized or eliminated entirely.

\section{PROGRESS TOWARD ORGAN CRYOPRESERVATION BY VITRIFICATION}

The possibility of avoiding ice formation by depressing the freezing point to temperatures approaching the sublimation temperature of dry ice $\left(-79^{\circ} \mathrm{C}\right)$ was first demonstrated for red blood cells by Huggins ${ }^{45}$ and for guinea pig uteri by Farrant ${ }^{46}$ in 1965 . However, the problem of vascular integrity was not explicitly addressed in these studies, nor was the problem of delivering and removing cryoprotectants by perfusion. In addition, these studies resulted in storage in the liquid state, which is inadequate for truly long-term changeless storage. Finally, attempts to apply Farrant's method to kidneys $^{47-50}$ and even to kidney slices ${ }^{24,51}$ were not successful.

The method proposed by Huggins and Farrant involved equilibrium depression of the freezing point by the colligative action of cryoprotective agents. A more sophisticated and practical plan for eliminating ice entirely even at the temperature of liquid nitrogen was proposed by Fahy in the 1980s. ${ }^{28,29,52,53}$ This method involved the use of carefully balanced cocktails of cryoprotective agents in sufficiently high concentrations to permit clear-cut supercooling into the glassy state, a process known as vitrification, rather than equilibrium freezing point depression. ${ }^{53} \mathrm{~A}$ glass is a liquid whose fluidity has been lost as a result of extreme elevation in viscosity produced by cooling to or below the glass transition temperature $\left(\mathrm{T}_{\mathrm{G}}\right.$, the temperature at which vitrification occurs). ${ }^{29}$ By supercooling into the glassy state, the concentration of cryoprotectant needed for preservation was actually reduced in comparison to Huggins and Farrant's equilibrium method, and the exact concentration needed for vitrification $\left(\mathrm{C}_{\mathrm{V}}\right)$ was shown to be predictable from phase diagram information. ${ }^{29,53}$ Furthermore, before Fahy's method was suggested, vitrification generally was thought to require very rapid cooling rates unattainable for objects the size of whole organs, ${ }^{54,55}$ and a key aspect of Fahy's proposal was the ability to transcend this limitation. The misconception that vitrification requires ultrarapid cooling has been difficult to correct, but the demonstration of applicability to whole rabbit kidneys $(\sim 11 \mathrm{~mL})$ in $1984^{29}$ and $2004^{27}$ and to volumes of up to $2 \mathrm{~L}$ or more in $2005^{56}$ is gradually making the broad potential utility of vitrification at low cooling rates more apparent.

Fahy's proposal, although developed to solve the problems of cryopreserving organs, rapidly became popular for the preservation of simpler systems, in part because it eliminated the need for controlled rate freezing machines and allowed prepared samples to be preserved by direct immersion in liquid nitrogen. ${ }^{57}$ The initial proof of principle for the method, in 1985, was the successful preservation of mouse embryos by vitrification, ${ }^{57}$ an accomplishment that continues to influence much research in reproductive cryobiology, including the cryopreservation of ova for extending the reproductive lifespan of women. ${ }^{3,30}$ An indication of the growth of this field is provided in Figure 2. The projected number of PubMed citations for vitrification as a method of cryopreservation was expected to reach approximately 600 by the end of 2005.

As might be expected, application of Fahy's method to large organs was less straightforward. The approach required perfusion of or- 


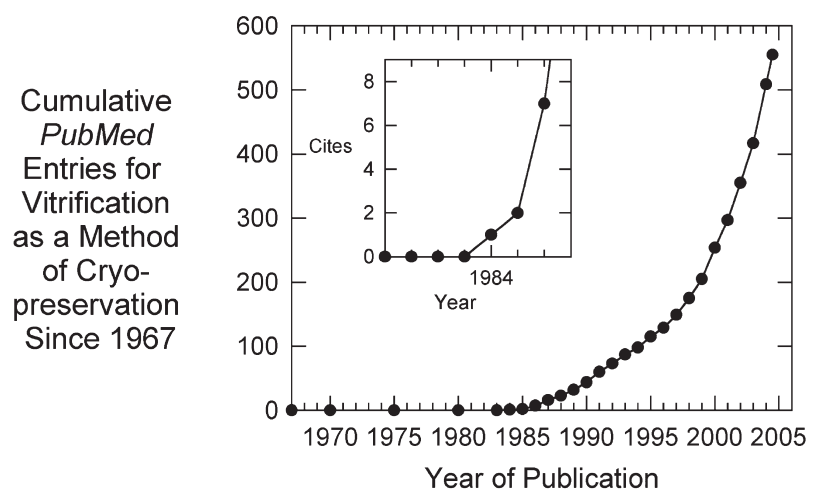

FIG. 2. Popularity of vitrification as an approach to cryopreservation, as measured by the cumulative number of citations in PubMed to the use of the method to preserve living systems at cryogenic temperatures. The onset of the curve in 1984 is from: Fahy GM, MacFarlane DR, Angell CA, Meryman HT. Vitrification as an approach to cryopreservation. Cryobiology 1984;21:407-426. The first proof of principle of the method in 1985 is from: Rall WF, Fahy GM. Ice-free cryopreservation of mouse embryos at $-196^{\circ} \mathrm{C}$ by vitrification. Nature 1985; 313:573-575.

gans with multimolar concentrations of cryoprotectant at relatively high temperatures. For this to be possible, new equipment, software, and protocols for automated cryoprotectant perfusion had to be created, ${ }^{58}$ and new mixtures of cryoprotectants with less toxicity than anything available previously ${ }^{29,59-62}$ also had to be developed. However, once these new tools were in hand, steady progress and a series of fundamentally new advances were achieved.

The most encouraging initial development was the attainment of immediate renal function in vitro in about half of rabbit kidneys perfused with $7.5 \mathrm{M}$ cryoprotectant. ${ }^{63}$ This was followed shortly thereafter by $100 \%$ survival and retention of full histologic integrity after transplantation of kidneys perfused with $7.5 \mathrm{M}$ cryoprotectant at $-3^{\circ} \mathrm{C} .{ }^{64}$ However, this concentration, as enormous as it was, was insufficient for vitrification unless cooling was carried out under elevated hydrostatic pressure. ${ }^{59,63}$ Raising the total concentration to $8.4 \mathrm{M}$ cryoprotectant to permit vitrification at ambient pressure was sufficient to allow the successful preservation of several simpler tissues (blood vessels, heart valves, and rabbit cartilage) by vitrification. ${ }^{65}$ However, the survival rate of kidneys perfused with this $8.4 \mathrm{M}$ solution (known variously as VS55 or VS41A $)^{59}$ was $0 \%$ at $-3^{\circ} \mathrm{C}$ and only about $50 \%$ when the kidneys were manually cooled to about $-20^{\circ} \mathrm{C}$ while containing $6.7 \mathrm{M}$ cryoprotectant before introducing VS41A. ${ }^{66} \mathrm{It}$ was apparent that further breakthroughs were needed, not only because of the damage caused by VS41A even at $-20^{\circ} \mathrm{C}^{67}$ but also because kidneys vitrified with this cocktail could not be rewarmed without freezing on rewarming (devitrification), ${ }^{65}$ a problem that negates the advantage of previous vitrification. Also, although many alternatives to VS41A have been used with success for the vitrification of relatively simple systems such as the cornea ${ }^{68}$ and probably the mouse ovary ${ }^{69}$ and ovarian tissue from several species, ${ }^{70}$ none of these alternative solutions is likely to be less toxic than VS41A. ${ }^{30}$

In 1998, another pivotal and fundamental breakthrough took place in the technology of cryoprotectant solution formulation that allowed cryoprotectant toxicity to be understood as a consequence of reduced water availability for the hydration of cellular biomolecules. ${ }^{30}$ This insight allowed drastically less toxic solutions to be designed. For example, kidneys consistently experienced no postoperative creatinine peak (i.e., sustained zero damage) after perfusion at $-3^{\circ} \mathrm{C}$ with a new solution called VMP that, like VS41A, has a total concentration of $8.4 \mathrm{M}$ (Fig. 3). ${ }^{30}$ However, although VMP is very concentrated, it is still too dilute to escape from devitrification on warming at easily achievable warming rates for large organs; therefore, additional innovations were still required.

The next major practical step forward was the development of a working ultrastable vitrifiable solution, M22. M22 contains two novel antinucleating substances ("ice blockers") that are dramatically effective in reducing the probability of ice formation. ${ }^{71-73}$ It also contains a physiologic support solution (the "carrier solution" or vehicle for M22 cryoprotectants), LM5, that is compatible with the new "ice blockers." ${ }^{27}$ M22 attains further stability by including a novel polymer that is capable of significantly slowing ice crystal growth ${ }^{27}$ and has an ideal tonicity for blocking "chilling injury" (an ill-understood form of injury caused by 


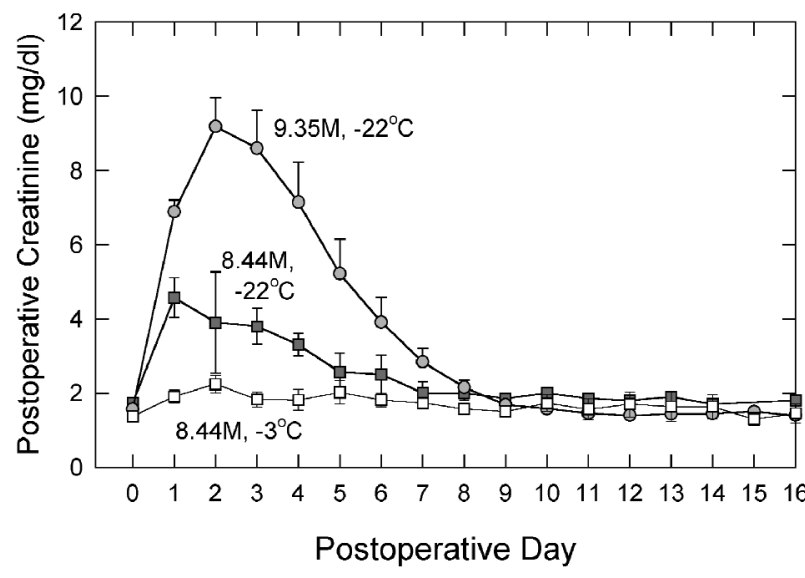

FIG. 3. Effects of perfusing the $8.44 \mathrm{M}$ VMP solution through rabbit kidneys at $-3^{\circ} \mathrm{C}$ (lower curve), cooling them to $-22^{\circ} \mathrm{C}$ while continuing perfusion with VMP (middle curve), and perfusing them with the 9.345M M22 solution at $-22^{\circ} \mathrm{C}$ after perfusion-cooling with VMP (upper curve). All kidneys were transplanted back to their original donors after rewarming and cryoprotectant washout, and an immediate contralateral nephrectomy was performed. $n$ values are 7,3 , and 10 for VMP at $-3^{\circ} \mathrm{C}$, VMP at $-22^{\circ} \mathrm{C}$, and $\mathrm{M} 22$ at $-22^{\circ} \mathrm{C}$, respectively. There were no nonsurvivors in any of these groups. For further discussion, see text. Data collected from: Fahy GM, Wowk B, Wu J, Phan J, Rasch C, Chang A, Zendejas E. Cryopreservation of organs by vitrification: perspectives and recent advances. Cryobiology 2004;48:157-178; Fahy GM, Wowk B, Wu J, Paynter S. Improved vitrification solutions based on predictability of vitrification solution toxicity. Cryobiology 2004; 48:22-35. cooling per se). ${ }^{27}$ Finally, M22 contains a novel low-toxicity, strongly glass-forming, and highly permeable methoxylated cryoprotec$\operatorname{tant}^{74}$ and a highly permeating novel amide. ${ }^{27}$ M22 (so named because it is intended for use at $\left.-22^{\circ} \mathrm{C}\right)$, has extraordinary physical properties (Table 3); however, when used in renal cortical slice toxicity screening assays, it yielded $>90 \%$ recovery of ion transport function. ${ }^{27}$

Accordingly, the next step was to test M22 on whole kidneys. To do this, perfusion-cooling and -warming methods had to be worked out to allow continuous perfusion of the organ during cooling to and warming from about $-22^{\circ} \mathrm{C}$. Figure 3 assembles the "bottom line" of several series of optimization experiments 27,30 relevant to the evaluation of M22. The lower curve shows the net effects of perfusing VMP at about $-3^{\circ} \mathrm{C}$ (baseline conditions), demonstrating the remarkable lack of damage associated with this treatment. The second curve shows the effect of cooling kidneys to $-22^{\circ} \mathrm{C}$ with VMP using an optimized protocol. Again, little damage is observed, attesting to the success of VMP at inhibiting "chilling injury" at $-22^{\circ} \mathrm{C}$. Finally, the upper curve shows the effect of perfusing to $-22^{\circ} \mathrm{C}$ with VMP and then, at $-22^{\circ} \mathrm{C}$, switching to $\mathrm{M} 22$ and perfusing with

Table 3. Physical Properties of M22 a

\begin{tabular}{lc}
\hline Property & Value \\
\hline Total concentration, g/L & 684 \\
Total concentration, molar & 9.345 \\
Number of specific-function cryoprotectants & 8 \\
Melting point $\mathrm{b}^{\mathrm{b}}$ & $\sim-54.9^{\circ} \mathrm{C}$ \\
Glass transition temperature & $-123.3^{\circ} \mathrm{C}$ \\
Lowest cooling rate supporting no ice in 2 liters & $1^{\circ} \mathrm{C} / \mathrm{min}$ \\
Lowest warming rate supporting no ice & $4^{\circ} \mathrm{C} / \mathrm{min}$ \\
\hline
\end{tabular}

aThe complete formula for M22 is given in Fahy GM, Wowk B, Wu J, Phan J, Rasch C, Chang A, Zendejas E. Cryopreservation of organs by vitrification: perspectives and recent advances. Cryobiology 2004;48:157-178.

The properties of M22 have been described in more detail in Fahy GM, Wowk B, Wu J, Phan J, Rasch C, Chang A, Zendejas E. Cryopreservation of organs by vitrification: perspectives and recent advances. Cryobiology 2004;48:157-178; Wowk B, Fahy GM, Toward large organ vitrification: extremely low critical cooling and warming rates of M22 vitrification solution. Cryobiology 2005;51:362.

${ }^{\mathrm{b}}$ The melting point was estimated from an extrapolation of the melting point curve of dilutions of M22 because M22 itself could not be frozen. See: Fahy GM, Wowk B, Wu J, Phan J, Rasch C, Chang A, Zendejas E. Cryopreservation of organs by vitrification: perspectives and recent advances. Cryobiology 2004;48: 157-178.

${ }^{\mathrm{C}}$ The glass transition temperature was measured at a warming rate of $2{ }^{\circ} \mathrm{C} / \mathrm{min}$. 
M22 for up to 25 minutes, followed by optimized rewarming to $-3^{\circ} \mathrm{C}$ and washout with VMP. The introduction of M22 produced more damage than cooling to $-22^{\circ} \mathrm{C}$ alone, but the damage was limited and entirely reversible within a clinically normal period of time and was less than is typically accepted in clinical human kidney transplantation today.

The next step was to test the significance of chilling injury at temperatures below $-22^{\circ} \mathrm{C}$. For these experiments, the authors removed the kidneys from our perfusion machine and cooled them in a rapidly moving cold atmosphere set to a temperature just below $-50^{\circ} \mathrm{C}$. When all parts of the kidney were between $-40^{\circ} \mathrm{C}$ and $-50^{\circ} \mathrm{C}$ (except for the outer cortex, which was presumably below $-50^{\circ} \mathrm{C}$ ), the organs were placed back into the perfusion machine and were rewarmed back to $-22^{\circ} \mathrm{C}$ by external lavage with M22, then further warmed and washed free of M22 as usual. This procedure produced a substantial increase in injury compared to exposure to $-22^{\circ} \mathrm{C}$ alone (Fig. 4), but was survived by all kidneys in the series $(n=8)$, and final creatinine levels were all in the normal range. This was the first time the routine survival of any mammalian organ from a temperature approaching $-50^{\circ} \mathrm{C}$ (mean intrarenal temperature, about $-45^{\circ} \mathrm{C}$ ) had ever been achieved. ${ }^{27}$

The exact origin of this extra injury remained to be determined. Alternatives to chilling injury included the extra total exposure time to the cryoprotectant required during the added cooling and the rewarming phase back to $-22^{\circ} \mathrm{C}$ and injury related to the extra handling of the kidney and processes related to it. Very preliminary evidence $(n=2)$ suggests that the extra injury seen in the initial $-45^{\circ} \mathrm{C}$ experiments is not inevitable, and can be reduced or eliminated by improvements in technique (see Fig. 4). The question of whether this suppression of injury at $-45^{\circ} \mathrm{C}$ can be reproduced and extended to temperatures below $-45^{\circ} \mathrm{C}$ remains open, but will soon be the subject of intensive investigation. Information obtained with renal slices suggests chilling injury will continue to increase down to about $-80^{\circ} \mathrm{C}$, but nevertheless can be almost completely suppressed under optimum conditions. ${ }^{27}$
Although much work remains to be done, this is clearly a new era and most of what has to be done in order to achieve successful banking of complex, spatially extended living systems has been accomplished. In addition, recently the authors were able to attain the first direct proof-of-principle for organ vitrification by showing that a single rabbit kidney, after cooling to below $\mathrm{T}_{\mathrm{G}}$, rewarming, and reimplantation, was able to provide stable life support function until sacrificed on postoperative day 48 for histologic examination. ${ }^{75}$ This kidney sustained major histologic damage from inner medullary ice formation in some peripelvic columns, but no such damage in others. This suggests that the problem of more uniformly distributing M22 to the inner medulla will be vital to routine recovery from below $\mathrm{T}_{\mathrm{G}}$, and

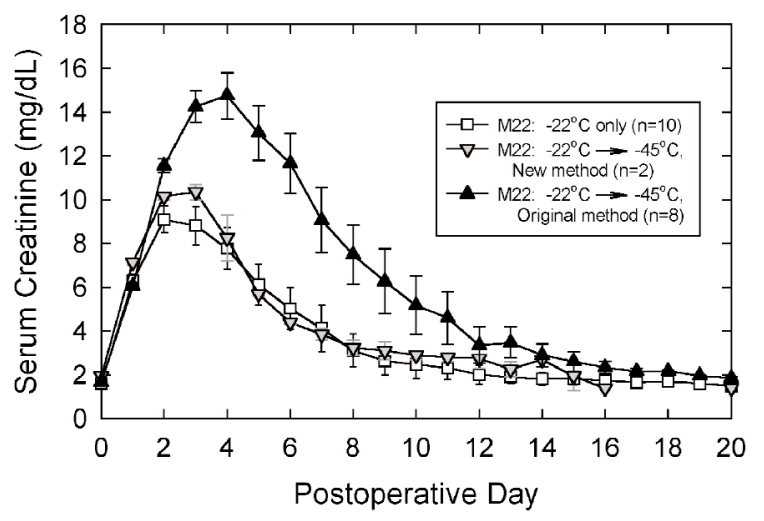

FIG. 4. Effects of cooling rabbit kidneys to a mean intrarenal temperature of $-45^{\circ} \mathrm{C}$ as measured using invasive needle thermocouple probes in parallel experiments (modified from: Fahy GM, Wowk B, Wu J, Phan J, Rasch C, Chang A, Zendejas E. Cryopreservation of organs by vitrification: perspectives and recent advances. Cryobiology 2004;48:157-178). In the first method (upper curve), injury was increased by this treatment and mimicked the effects of holding kidneys at $-22^{\circ} \mathrm{C}$ for a period similar to the time required for cooling from $-22^{\circ} \mathrm{C}$ to $-45^{\circ} \mathrm{C}$ and rewarming from $-45^{\circ} \mathrm{C}$ back to $-22^{\circ} \mathrm{C}$ (data not shown; see Fahy GM, Wowk B, Wu J, Phan J, Rasch C, Chang A, Zendejas E. Cryopreservation of organs by vitrification: perspectives and recent advances. Cryobiology 2004;48: 157-178). In the second method, in which exposure time was reduced, all of the injury observed at $-45^{\circ} \mathrm{C}$ was avoided. In method 2, Supercool X-1000 (Wowk B, Leitl E, Rasch CM, Mesbah-Karimi N, Harris SB, Fahy GM. Vitrification enhancement by synthetic ice blocking agents. Cryobiology 2000;40:228-236; Wowk B. Anomalous high activity of a subfraction of polyvinyl alcohol ice blocker. Cryobiology 2005;50:325-331) was omitted from M22 for reasons unrelated to this protocol, but this is not believed to have influenced the results. 
the authors are presently focused on solving this problem. In addition, continued improvement of cryoprotectant technology also is ongoing in their laboratory.

Finally, direct experiments on an artificial organ model, the Cordis-Dow Artificial Kidney (CDAK), have shown that whereas both the external housing and the internal parallel hollow fibers (blood path) of the CDAK are ruptured by ice expansion during freezing in the presence of $10 \%$ dimethyl sulfoxide and $0.9 \% \mathrm{NaCl}$, neither the housing nor the fibers appear to be damaged by vitrification or the hazard of devitrification on warming (Fig. 5). ${ }^{76}$ Thus, it appears that vitrification is likely to be compatible with both the living and nonliving components of future bioartificial organs.

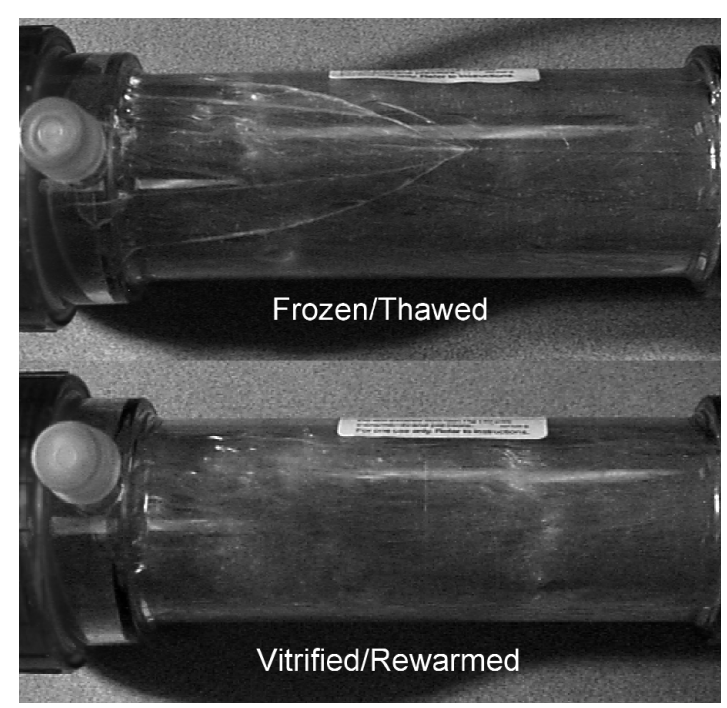

FIG. 5. Effects of freezing and thawing (top) and of vitrification and rewarming (bottom) on Cordis-Dow Artificial Kidneys (CDAKs). See: Fahy GM. The practicality of vitrification for cryopreservation of engineered tissues. Cryobiology 2001;43:349-350. The upper panel shows cracks formed in the housing of the CDAKs despite the use of $10 \% \mathrm{v} / \mathrm{v}$ dimethyl sulfoxide and $09 \% \mathrm{w} / \mathrm{v} \mathrm{NaCl}$ to limit ice formation as in a typical cell cryopreservation procedure. These cracks, shown after thawing and closure of the cracks, were several millimeters wide when fully open prior to thawing. The CDAKs are stained blue by the use of blue dextran $\left(2 \times 10^{6}\right.$ daltons $)$ as a marker of blood path permeability. Although blue dextran stained the hollow fibers in all kidneys, control CDAKs and vitrified-rewarmed CDAKs did not leak blue dextran from the blood path to the dialysate path, whereas the frozen-thawed CDAKs had dialysate path concentrations of blue dextran that were equivalent to those in the blood path, indicating complete breaching of the semipermeability of the hollow fibers. Note the lack of any fractures in the outer housing in the vitrified-rewarmed CDAK.

\section{CONCLUSION}

Cryopreservation currently plays an important role in the development of treatments for aging through such pathways as the preservation of stem cells and human ova and is likely to be an increasingly key factor in the success of regenerative medicine as this field progresses. Future cell-based therapeutics will have to be stored before use, and organized tissues and organ-like devices will probably not escape from this requirement. Fortunately, the science of cryopreservation is rapidly advancing and may be equal to the task of preserving even complex bioartificial implants when the time comes. In the meantime, there is evidence that low-toxicity vitrification solutions for whole organs may have applications for many simpler tissue replacements now, and even single cells subjected to freezing and thawing may benefit from the new technical advances in organ banking. Freezing can concentrate ordinary cryoprotectant solutions to toxic levels in the frozen state even when single cells are frozen, and this effect is known to be suppressed by using cryoprotectants that are less toxic even when greatly freeze-concentrated. ${ }^{77}$ Therefore, until the long-sought goal of perpetual youth can be achieved by purely pharmaceutical and/or genetic adjustments, cryopreservation is likely to continue to be an important factor for the advanced treatment of human aging.

\section{ACKNOWLEDGMENTS}

This work was supported entirely by 21st Century Medicine, Inc. The authors thank Alice Chang and David Ta for expert surgical assistance and Darren Bell for careful assistance with the CDAK experiments. For more information on 21st Century Medicine and its products and services, see http://www. $21 \mathrm{~cm} . \mathrm{com}$.

\section{REFERENCES}

1. Ji L, de Pablo JJ, Palecek sP. Cryopreservation of adherent human embryonic stem cells. Biotechnol Bioeng 2004;88:299-312.

2. Klimanskaya I, Chung Y, Meisner L, Johnson J, West 
MD, Lanza R. Human embryonic stem cells derived without feeder cells. Lancet 2005;365:1636-1641.

3. Gosden R. Prospects for oocyte banking and in vitro maturation. J Natl Cancer Inst Monogr 2005;34:60-63.

4. Hovatta O. Methods for cryopreservation of human ovarian tissue. Reproduct Biomed Online 2005;10: 729-734.

5. Perkins EH, Makinodan T, Seibert C. Model approach to immunological rejuvenation of the aged. Infect Immunol 1972;6:518-524.

6. Posselt AM, Barker CF, Tomaszewski JE, Markmann JF, Choti MA, Naji A. Induction of donor-specific unresponsiveness by intrathymic islet transplantation. Science 1990;249:1293-1295.

7. Remuzzi G, Rossini M, Imberti O, Perico N. Kidney graft survival in rats without immunosuppressants after intrathymic glomerular transplantation. Lancet 1991;337:750-752.

8. Lysaght MJ, Reyes J. The growth of tissue engineering. Tiss Eng 2001;7:485-493.

9. Lysaght MJ, Hazlehurst AL. Tissue engineering: the end of the beginning. Tiss Eng 2004;10:309-320.

10. Table 1. Natl Vital Stat Rept 2002;50(16):15-48.

11. Fahy GM. Apparent induction of partial thymic regeneration in a normal human subject: a case report. J Anti-aging Med 2003;6:219-227.

12. Une S, Kenmochi T, Miyamoto M, Nakagawa $Y$, Benhamou PY, Sangkharat A, Mullen Y. Induction of donor-specific unresponsiveness in NIH minipigs following intrathymic islet transplantation. Transplant Proc 1995;27:142-144.

13. Liu C, Deng S, Jiang K, Liu W, Kenyon N, Ricordi C, Naji A, Barker C, Brayman K. Long-term survival following canine intrathymic islet allograft transplantation with short-course immunosuppressive therapy. Transplant Proc 2001;33:561.

14. Fahy GM. Growth hormone therapy and related methods and pharmaceutical compositions. US Patent 6,297,212 B1, 2001.

15. Trivedi HL, Vanikar AV, Modi PR, Shah VR, Vakil JM, Trivedi VB, Khemchandani SI. Allogeneic hematopoietic stem-cell transplantation, mixed chimerism, and tolerance in living related donor renal allograft recipients. Transplant Proc 2005;37:737-742.

16. Salgar SK, Shapiro R, Dodson F, Corry R, McCurry K, Zeevi A, Pham S, Abu-Elmagd K, Reyes J, Jordan M, Keenan R, Griffith B, Sesky T, Ostrowski L, Starzl TE, Fung JJ, Rao AS. Infusion of donor leukocytes to induce tolerance in organ allograft recipients. J Leukocyte Biol 1999;66:310-314.

16a. Sykes M. Immune tolerance induction: from bench to bedside. Rejuvenation Res 2005;8(Suppl 1):S51 [abstract].

17. Naughton GK. From lab bench to market, critical issues in tissue engineering. Ann NY Acad Sci 2002; 961:372-385.

18. Karlsson JO, Toner M. Cryopreservation. In: Lanza RP, Langer R, Vacanti J, eds. Principles of Tissue Engineering, 2nd ed. San Diego: Academic Press, 2000:293-307.
19. Amado LC, Saliaris AP, Schuleri KH, St John M, Xie JS, Cattaneo S, Durand DJ, Fitton T, Kuang JQ, Stewart G, Lehrke S, Baumgartner WW, Martin BJ, Heldman AW, Hare JM. Cardiac repair with intramyocardial injection of allogeneic mesenchymal stem cells after myocardial infarction. Proc Natl Acad Sci USA 2005;102:11474-11479.

20. Nadal-Ginard B, Anversa P, Kajstura J, Leri A. Cardiac stem cells and myocardial regeneration. Novartis Found Symp 2005;265:142-157, 204-211.

21. Menasche P. The potential of embryonic stem cells to treat heart disease. Curr Opin Mol Ther 2005;7:293-299.

22. Leferovich JM, Bedelbaeva K, Samulewicz S, Zhang XM, Zwas D, Lankford EB, Heber-Katz E. Heart regeneration in adult MRL mice. Proc Natl Acad Sci USA 2001;98:9830-9835.

22a. Holm TM, Jackson-Grusby L, Bambrick T, Yamada Y, Rideout WM, III, Jaenisch R. Global loss of im printing in embryonic stem cells leads to widespread tumorigenesis in adult mice. Rejuvenation Res 2005;8(Suppl 1):S33 [abstract].

23. Lanza RP, Langer R, Vacanti J. Principles of Tissue Engineering, 2nd ed. San Diego: Academic Press, 2000.

24. Fahy GM. Analysis of "solution effects" injury: rabbit renal cortex frozen in the presence of dimethyl sulfoxide. Cryobiology 1980;17:371-388.

25. Balasubramanian SK, Coger RN. Heat and mass transfer during the cryopreservation of a bioartificial liver device: a computational model. ASAIO J 2005;51: 184-193.

25a. Ratner BD. To engineer a heart. Rejuvenation Res 2005;8(Suppl 1):S46 [abstract].

26. Lanza RP, Chung HY, Yoo JJ, Wettstein PJ, Blackwell C, Borson N, Hofmeister E, Schuch G, Soker S, Moraes CT, West MD, Atala A. Generation of histocompatible tissues using nuclear transplantation. Nat Biotechnol 2002;20:689-696.

26a. Atala A. Tissue engineering, stem cells and cloning: current concepts and changing trends. Rejuvenation Res 2005;8(Suppl 1):S20-S21 [abstract].

27. Fahy GM, Wowk B, Wu J, Phan J, Rasch C, Chang A, Zendejas E. Cryopreservation of organs by vitrification: perspectives and recent advances. Cryobiology 2004;48:157-178.

28. Fahy GM. Vitrification: a new approach to organ cryopreservation. Prog Clin Biol Res 1986;224:305-335.

29. Fahy GM, MacFarlane DR, Angell CA, Meryman HT. Vitrification as an approach to cryopreservation. Cryobiology 1984;21:407-426.

30. Fahy GM, Wowk B, Wu J, Paynter S. Improved vitrification solutions based on predictability of vitrification solution toxicity. Cryobiology 2004;48:22-35.

31. Smith AU. The effects of glycerol and of freezing on mammalian organs. In: Smith AU, ed. Biological Effects of Freezing and Supercooling. London: Edward Arnold, 1961:247-269.

32. Hamilton R, Holst HI, Lehr HB. Successful preservation of canine small intestine by freezing. J Surg Res 1973;14:313-318. 
33. Wang $X$, Chen $H$, Yin $H$, Kim S, Lin Tan S, Gosden R. Fertility after intact ovary transplantation. Nature 2002;415:385.

34. Harp R, Leibach J, Black J, Keldahl C, Karow AM Jr. Cryopreservation of murine ovarian tissue. Cryobiology 1994;31:336-343.

35. Gunasena KT, Villines PM, Critser ES, Critser JK. Live births after autologous transplant of cryopreserved mouse ovaries. Hum Reprod 1997;12:101-106.

36. Carroll J, Gosden R. Transplantation of frozenthawed mouse primordial follicles Hum Reprod 1993;8:1163-1167.

37. Bedaiwy MA, Jeremias E, Gurrrunluoglu R, Hussein MR, Siemianow M, Biscotti C, Falcone T. Restoration of ovarian function after autotransplantation of intact frozen-thawed sheep ovaries with microvascular anastomosis. Fertil Steril 2003;79:594602.

38. Arav A. Large tissue freezing. J Assist Reprod Genet 2003;20:351.

39. Arav A, Revel A, Nathan Y, Bor A, Gacitua H, Yavin S, Gavish Z, Uri M, Elami A. Oocyte recovery, embryo development and ovarian function after cryopreservation and transplantation of whole sheep ovary. Hum Reprod 2005;20:3554-3559.

40. Pegg DE. Ice crystals in tissues and organs. In: Pegg DE, Karow AM Jr, eds. The Biophysics of Organ Cryopreservation. New York: Plenum, 1987:117-140.

41. Pollack GA, Pegg DE, Hardie IR. An isolated perfused rat mesentery model for direct observation of the vasculature during cryopreservation. Cryobiology 1986; 23:500-511.

42. Pegg DE, Diaper MP. The mechanism of cryoinjury in glycerol-treated rabbit kidneys. In: Pegg DE, Jacobsen IA, Halasz NA, eds. Organ Preservation, Basic and Applied Aspects. Lancaster, UK: MTP Press, 1982:389-393.

43. Hunt CJ. Studies on cellular structure and ice location in frozen organs and tissues: the use of freeze-substitution and related techniques. Cryobiology 1984;21: 385-402.

44. Fahy GM. Analysis of "solution effects" injury: cooling rate dependence of the functional and morphological sequellae of freezing in rabbit renal cortex protected with dimethyl sulfoxide. Cryobiology 1981; 18:550-570.

45. Huggins CE. Preservation of organized tissues by freezing. Fed Proc 1965;(Suppl 15):S190-S195.

46. Farrant J. Mechanism of cell damage during freezing and thawing and its prevention. Nature 1965;205: 1284-1287.

47. Kemp E, Clark PB, Anderson CK, Parsons FM. Longterm preservation of the kidney. Proc Eur Dial Transplant Assoc 1966;3:236-240.

48. Kemp E, Clark PB, Anderson CK, Laursen T, Parsons FM. Low temperature preservation of mammalian kidneys. Scand J Urol Nephrol 1968;2:183-190.

49. Uldall PR, Keeler R, Swinney J, Taylor RMR. Some studies in cooling and perfusion of kidneys. Proc Eur Dial Transplant Assoc 1966;3:241-244.
50. Carruthers RK, Clark PB, Anderson CK, Parsons FM. Tubular function demonstrated in rat kidneys after storage at $-79^{\circ} \mathrm{C}$. Br J Urol 1969;41:186-189.

51. Fahy GM. Correlations Between Cryoinjury in Mammalian Systems and Changes in the Composition and Properties of the Extracellular Milieu During Freezing. Dissertation, Department of Pharmacology, Medical College of Georgia, Augusta, GA, 1977.

52. Fahy GM. Prospects for vitrification of whole organs. Cryobiology 1981;18:617.

53. Fahy GM, Hirsh A. Prospects for organ preservation by vitrification. In: Pegg DE, Jacobsen IA, Halasz NA, eds. Organ Preservation, Basic and Applied Aspects. Lancaster, UK: MTP Press, 1982:399-404.

54. Luyet B. On the amount of water remaining amorphous in frozen aqueous solutions. Biodynamica 1969;10:277-291.

55. Fahy GM. Vitrification. In: Diller K, McGrath J, eds. Low Temperature Biotechnology: Emerging Applications and Engineering Contributions. New York: American Society for Mechanical Engineering, 1988:113-146.

56. Wowk B, Fahy GM, Toward large organ vitrification: extremely low critical cooling and warming rates of M22 vitrification solution. Cryobiology 2005;51:362.

57. Rall WF, Fahy GM. Ice-free cryopreservation of mouse embryos at $-196^{\circ} \mathrm{C}$ by vitrification. Nature 1985;313:573-575.

58. Fahy GM. Organ perfusion equipment for the introduction and removal of cryoprotectants. Biomed Instrument Technol 1994;28:87-100.

59. Fahy GM, da Mouta C, Tsonev L, Khirabadi BS, Mehl $\mathrm{P}$, Meryman HT. Cellular injury associated with organ cryopreservation: chemical toxicity and cooling injury. In: Lemasters JJ, Oliver C, eds. Cell Biology of Trauma. Boca Raton, FL: CRC Press, 1995:333-356.

60. Fahy GM. Prevention of toxicity from high concentrations of cryoprotective agents. In: Pegg DE, Jacobsen IA, Halasz NA, eds. Organ Preservation, Basic and Applied Aspects. Lancaster, UK: MTP Press, 1982:367-369.

61. Fahy GM, Levy DI, Ali SE. Some emerging principles underlying the physical properties, biological actions, and utility of vitrification solutions. Cryobiology 1987;24:196-213.

62. Fahy GM, Lilley TH, Linsdell H, St. John Douglas M, Meryman HT. Cryoprotectant toxicity and cryoprotectant toxicity reduction: in search of molecular mechanisms. Cryobiology 1990;27:247-268.

63. Fahy GM, Ali SE. Cryopreservation of the mammalian kidney. II. Demonstration of immediate ex vivo function after introduction and removal of $7.5 \mathrm{M}$ cryoprotectant. Cryobiology 1997;35:114-131.

64. Khirabadi B, Fahy GM. Permanent life support by kidneys perfused with a vitrifiable (7.5 molar) cryoprotectant solution. Transplantation 2000;70:51-57.

65. Taylor MJ, Song YC, Brockbank KG. Vitrification in tissue preservation: new developments. In: Fuller BJ, Lane N, Benson EE, eds. Life in the Frozen State. Boca Raton, FL: CRC Press, 2004:603-641. 
66. Khirabadi BS, Fahy GM, Ewing LS. Survival of rabbit kidneys perfused with $8.4 \mathrm{M}$ cryoprotectant. Cryobiology 1995;32:543-544.

67. Arnaud FG, Khirabadi B, Fahy GM. Physiological evaluation of a rabbit kidney perfused with VS41A. Cryobiology 2003;46:289-294.

68. Armitage WJ, Hall SC, Routledge C. Recovery of endothelial function after vitrification of cornea at $-110^{\circ} \mathrm{C}$. Invest Ophthalmol Vis Sci 2002;43:2160 2164.

69. Migishima F, Suzuki-Migishima R, Song S-Y, Kuramochi T, Azuma S, Nishijima M, Yokoyama M. Successful cryopreservation of mouse ovaries by vitrification. Biol Reprod 2003;68:881-887.

70. Kagabu S, Umezu M. Transplantation of cryopreserved mouse, chinese hamster, rabbit, Japanese monkey and rat ovaries into rat recipients. Exp Animal 2000;49:17-21.

71. Wowk B, Leitl E, Rasch CM, Mesbah-Karimi N, Harris SB, Fahy GM. Vitrification enhancement by synthetic ice blocking agents. Cryobiology 2000;40:228-236.

72. Wowk B, Fahy GM. Inhibition of bacterial ice nucleation by polyglycerol polymers. Cryobiology 2002;44: 14-23.
73. Wowk B. Anomalous high activity of a subfraction of polyvinyl alcohol ice blocker. Cryobiology 2005;50: 325-331.

74. Wowk B, Darwin M, Harris SB, Russell SR, Rasch CM. Effects of solute methoxylation on glass-forming ability and stability of vitrification solutions. Cryobiology 1999;39:215-227.

75. Fahy GM. Vitrification as an approach to cryopreservation: general perspectives. Cryobiology 2005;51: 348-349.

76. Fahy GM. The practicality of vitrification for cryopreservation of engineered tissues. Cryobiology 2001; 43:349-350.

77. Fahy GM. The relevance of cryoprotectant "toxicity" to cryobiology. Cryobiology 1986;23:1-13.

Address reprint requests to: Gregory M. Fahy, Ph.D. 21st Century Medicine, Inc. 10844 Edison Court

Rancho Cucamonga, CA 91730

E-mail: gfahy@21cm.com 